\title{
REPRESENTAÇÕES E PRÁTICAS DOCENTES NAS CARTAS DE QUEIXAS DA PROVÍNCIA DA PARAÍBA NO IMPÉRIO
}

Maria Géssica Romão Silva

Fabiana Sena $^{(*)}$

A carta é uma modalidade de escrita mais conhecida, desde a Antiguidade até os dias atuais, assumindo agora, outros suportes, a exemplo do e-mail. No período do Império brasileiro, a escrita de cartas nos jornais representou à sociedade da época uma forma de marcar o seu lugar ao expor queixas, dúvidas, opiniões e indagações sobre diversos assuntos. Para os historiadores da educação, a possibilidade de utilizar as cartas publicadas nos jornais como fonte e objeto de estudo propiciou uma nova forma de entender um dado período por vestígios deixados pelos sujeitos escrevedores de cartas. Nessa perspectiva, Burke (1992, p. 11) afirma que "o que era previamente considerado imutável [na história] é agora encarado como uma 'construção cultural', sujeita a variações, tanto no tempo como no espaço".

Neste sentido, o objetivo deste trabalho é analisar as representações e práticas docentes nas cartas de queixas escritas por professores e publicadas nos jornais da Paraíba em O Publicador (1862-1886), O Tempo (1864-1889) e Gazeta do Sertão (1880-1891). Faz-se necessário ressaltar que os anos citados correspondem ao período de circulação desses jornais, pois tão-somente utilizamos os anos correspondentes à disponibilidade na internet: $O$ Publicador (1864-1869), $O$ Tempo (1865) e Gazeta do Sertão (1888-1889). ${ }^{1}$ Para a compreensão do objeto, foi considerado o conteúdo desses jornais, na tentativa de compreender como eles se posicionavam e como propalavam seus ideais. Nestas analisam-se, a partir das práticas docentes, testemunhadas por um de seus principais protagonistas, o professor. Escritos de queixas protestam contra a realidade vivenciada por esses professores e consistem em formas de resistências que conduzem a instrução pública no Império paraibano, em razão dos indícios encontrados nos escritos epistolares dos professores nos jornais da Paraíba na época do Império.

\footnotetext{
(*) Maria Géssica Romão Silva. Mestre em Educação pela Universidade Federal da Paraíba. E-mail: gessicaromao@hotmail.com.

Fabiana Sena. Doutora em Educação. Professora do Departamento de Metodologia da Educação e do Programa de Pós-Graduação em Educação da Universidade Federal da Paraíba. E-mail: fabianasena @ yahoo.com.br.

${ }^{1}$ Estes jornais se encontram no site da hemeroteca digital: http://bndigital.bn.br/hemeroteca-digital/
} 
Para a análise do conteúdo das cartas, entendemos que as suas caracterizações e o discurso dos professores nelas se deram na perspectiva de Foucault por compreender que:

[...] em toda a sociedade a produção do discurso é simultaneamente controlada, selecionada, organizada e redistribuída por um certo número de procedimentos que têm por papel exorcizarlhe os poderes e os perigos, refrear-lhe o acontecimento aleatório, disfarçar a sua pesada, temível materialidade (FOUCAULT, 1971 [1970], p. 13).

Assim também nos apropriamos do conceito de representação de Chartier para entender o discurso nas cartas como "[...] instrumento de um conhecimento mediato que faz ver um objeto ausente substituindo-lhe uma 'imagem' capaz de repô-lo em memória e de 'pintá-lo' tal como é" (CHARTIER, 1991, p. 184).

\section{O GÊNERO DISCURSIVO EPISTOLAR: COMO AS CARTAS SE APRESENTAVAM NOS JORNAIS DA PROVÍNCIA DA PARAÍBA (1862-1891)?}

O gênero epistolar adota diversas formas no jornal, servindo para comunicar algo a alguém, reclamar, solicitar, solucionar algum problema, agradecer, anunciar ou ofertar trabalho e para tantos outros fins. No século XIX, as pessoas utilizavam a imprensa como meio de comunicação com o outro ao seu redor e era por meio da carta publicada no jornal que esse discurso era selado. $\mathrm{O}$ ato de escrever cartas, notemos:

[...] não encerra em si tão-somente o aspecto primordial da comunicação. Há no ato da escrita da carta todo um ritual que qualquer outro meio de comunicação não pode manter. A escrita de uma carta tem o seu tempo próprio, tem o seu ritmo próprio. Nela se escolhe o que se vai dizer, pesam-se muito bem os prós e os e os contras, sabe-se até onde ir, o que falar e o que calar (TIN, 2007, p. 243).

Escrever cartas para os jornais no século XIX era uma prática corrente entre as pessoas e uma forma de interagir na sociedade imperial. Assim, Sena $(2014$, p. 6) aponta que essa escrita tinha um lugar reservado no jornal que, muitas vezes, não havia um lugar fixo, de modo que:

[...] seção para realizar tal comunicação foi criada no jornal com o propósito de dar visibilidade a opinião de leitores ilustres e desconhecidos a respeito de um determinado assunto, cuja prática de escrita é ordinária. Entretanto, nem todos os jornais possuíam essa seção e, quando tinham, não era regular.

Um exemplo desse lugar incerto nas páginas do jornal pode ser encontrado n'O Publicador ${ }^{2}$, periódico da província da Paraíba, por exemplo, há uma coluna intitulada "Correspondências do

\footnotetext{
${ }^{2}$ O jornal $O$ Publicador (1862-1886) tinha impressão diária, com exceção dos domingos. Tal periódico era propriedade de José Rodrigues da Costa. Em sua tipografia de mesmo nome, o jornal era subscrito pelo valor de $1 \$ 000$ por mês. Tal valor deveria ser pago com antecedência pelos assinantes dos jornais. $\mathrm{O}$ jornal ao se comparar a uma empresa, diz ter
} 
Publicador", seção esta, como o próprio título anuncia, destinada a cartas. No entanto, nem todas as cartas desse jornal estavam na seção, sendo possível identificar algumas epístolas soltas ou ainda na seção "A Pedido".

Assim, constata-se que as cartas não tinham um local permanente no jornal, podendo ser encontradas da primeira à última página, dependendo do editorial, ou seja, o tipógrafo do jornal avalia o conteúdo propalado na carta a ser publicada, mas outros aspectos podem interferir no processo de circulação desse gênero discursivo, a exemplo do viés do jornal, do próprio signatário ou do destinatário da carta.

Mesmo nas cartas em que o signatário utilizava pseudônimos para preservar a real identidade, o recado alcançava seu destinatário, que, muitas vezes, respondia, seja no dia seguinte ao da publicação ou em números posteriores, o que “[...] expõe a força que o fator 'resposta' possui no relacionamento epistolar" (FREITAS, 2002, p. 61). Abaixo, há exemplos de cartas em que a resposta do destinatário é endereçada no mesmo jornal, em publicações diferentes.

Transação indecente. Contam-nos que um professor de instrucção primaria de um lugar distante quatro léguas ao sul da capital, tem justo e contratado pela quantia de dous contos de réis e cessão da casa em que funcciona a escola, a permuta de sua cadeira com um professor da freguesia de Santo Antonio. Accresce notar que esse professor do matto ainda é daquelles dos bons tempos em que não se conhecia a util instituição da Escola Normal. O negocio está em vias de conclusão: o Sr. Lucena, inteirado do facto, proceda como entender melhor para beneficio desta terra a qual elle tanto ama; uma vez que só depende de sua sancção a realisação dos sonhos desse mestre-escola tido e havido por analphabeto. (A PROVÍNCIA: ÓRGÃO DA PROVÍNCIA LIBERAL, 18 de fevereiro de 1874$)^{3}$.

Audacia inqualificável. O professor do matto desapontado ao ler a noticia publicada neste jornal sobre a transacção indecente que o mesmo quer fazer com outro seu colega, e vendo-se desta sorte burlado, exclamou: Hei de conseguir a permuta de minha cadeira, quer queria ou não Deus ou o Lucena, muito embora para isso seja preciso vender todos os prédios que tenho na Graça! Em breve estará na presidência o meu amigo Portella, e então, com o meu compadre Zé Thomaz, tudo arranjarei! O suspirata mia pemuta! Muito pode a audácia em um analphabeto! Muito vale ser compadre de presidente ou mesmo dos seus parentes!... (A PROVÍNCIA: ÓRGÃO DA PROVÍNCIA LIBERAL, 21 fev. 1874).

como dever "o facilitar convenientemente em suas colunas a liberdade de imprensa em toda a sua plenitude". Geralmente, o jornal O Publicador era composto pela "Parte Oficial"; - em que eram propalados os expedientes do Governo da Província, bem como os Despachos convenientes do mesmo - "Interior"; - em que se mencionavam as notícias correspondentes ao estrangeiro - "Noticiário"; "Comunicados"; "A Pedidos"; “Annuncios" e, por vezes, uma seção destinada às cartas, intitulada "Correspondências do Publicador".

${ }^{3}$ Mantem-se a ortografia da época. 
A carta indicada, publicada no jornal A Província: Órgão da Província Liberal ${ }^{4}$, com data de 18 de fevereiro de 1874, destinava-se ao "professor do matto", o qual, segundo o remetente, ensinava sem a qualificação da Escola Normal. Na província de Pernambuco, a primeira Escola Normal foi criada em 13 de maio de 1864, por meio da Lei 598. Peixoto (2006, p. 63) afirma que “[...] não poderia continuar a exercer o magistério, depois de dois anos de instalada essa escola, quem não fosse novamente examinado e aprovado no referido sistema".

No entanto, na prática, conforme denuncia a carta, havia "transações indecentes" que burlavam as regras. É o que aponta a resposta do dito "professor do matto", na carta enviada em edição posterior do mesmo jornal, com data de 21 de fevereiro de 1874, quando reconhece que "[...] muito pode a audácia em um analfabeto! Muito vale ser compadre de presidente ou mesmo dos seus parentes!...”. Essa representação da instrução pública, apresentada nas cartas, como negócio ou mercadoria e à mercê dos jogos de interesse, demonstra as relações existentes na sociedade imperial, na qual as trocas de favores eram constantes. Além disso, a relação de parentesco apontada nas cartas demonstrava as redes de sociabilidade existentes no período imperial. Nesse período, a própria identidade individual era confundida com o pertencimento a um grupo, o qual um indivíduo público carregaria ao se apresentar socialmente. Martins (2005, p. 2) elucida que:

Nessa estrutura social a própria identidade individual se encontrava fortemente vinculada às relações familiares e às redes às quais estas se associavam, o que fazia com que, com frequência, antes de serem homens públicos, os indivíduos representassem interesses e negócios dos grupos e famílias que os aproximaram do poder.

Muitas vezes as cartas aparecem, também, entre duas notícias que não têm, necessariamente, relação com o conteúdo da carta. Em outros momentos, a epístola se disfarça em outros gêneros discursivos, como a declaração, os editais, a notícia e/ou até o anúncio. Podemos verificar adiante uma epístola intitulada "edital”, que, apesar de apresentar-se sob esse gênero discursivo, esta possui as características que a definem como parte da escrita epistolar, a saber: o conteúdo, o destinatário, o signatário e a conclusão datada.

\footnotetext{
${ }^{4}$ O jornal A Província: Órgão do Partido Liberal tinha como gerente o senhor Minervino M. de S. Leão. A sua tipografia estava situada na Rua Duque de Caxias, $\mathrm{n}^{\circ} 50,1^{\circ}$ andar. Publicava-se nas terças e sextas. $\mathrm{O}$ jornal circulou na província de Pernambuco de 1872 a 1919 . Em Recife a assinatura do jornal custava $5 \$ 000$, o semestre, e $10 \$ 000$, o ano. Já no interior e em outras províncias, o valor passava a $6 \$ 000$ e $12 \$ 000$. O jornal possuía as seguintes seções: "A Província"; "Chonica"; "Folhetim"; "Interior"; "Exterior"; "Literatura" e "Transcrições".
} 


\section{EDITAL}

Pela directoria do lycêo desta cidade se manda fazer publico, para que chegue ao conhecimento de todos que acha-se aberta e continuara por todo anno a matricula de uma aula de Dezenho ultimamente creada no dito lycêo, cuja abertura teria lugar no dia 18 do corrente. Os que pretenderem frequental-a serão isentes de qualquer imposição. Secretaria do lycêo da cidade da Parahyba6 de julho de 1850 - O secretario do lycêo, Conselheiro Joaquim Bezerra Cavalcanti.

(O GOVERNISTA PARAHYBANO, 06 de julho de 1850).

Há algumas cartas nas quais o signatário demonstra querer alcançar um público maior, destinando-a não somente a uma pessoa, mas a um determinado grupo a quem o conteúdo poderia interessar. É o que podemos constatar na carta abaixo, que se destina aos "Srs. Pais de família e mais pessoas a cujo cargo ou tutella se achão os meninos que tem de frequentar a Aula publica de Primeiras Lettras do $2^{\circ}$ Districto desta Cidade".

- Para que os Srs. Pais de família e mais pessoas a cujo cargo ou tutella se achão os meninos que tem de frequentar a Aula publica de Primeiras Lettras do $2^{\circ}$ Destricto desta Cidade, fiquem inteirados de mais uma obrigação que se tem a cumprir d'ora em diante, faz-se a seguinte publicação.

OFFICIO.

N. 67. Determinando o art. 35 do Regulamento mandado executar pelo Decreto $\mathrm{n}^{\mathrm{o}} 464$ de 17 de agosto de 1846, que ninguém poderá ser admittido, matriculado, ou inscripto em qualquer Estabelecimento oficial ou Litterario - Publico ou particular - sem que mostre primeiramente que teve vaccina regular ou, bexigas naturaes, ou - que foi vacinado infructuosamente pelo menos trez vezes - Cumpre que V. Mce. não admitta na sua Escola menino algum sem que lhe prove por documento que tem satisfeito a disposição do Regulamento citado que tão providente e sábia é. Deus Guarde a V. Mce. Lyceo do Maranhão. 7 de Maio de 1849 - Dr. Cazimiro Jose de Moraes Sarmento. - Sr. Professor de primeiras lettras do $2^{\circ}$ Destricto de Caxias. (O TELEGRAFO, Maranhão, 09 de junho de 1849).

Outra característica utilizada, nessa carta, pelo signatário é o emprego de um ofício que regulamenta a instrução pública na época. O autor da carta, o "Dr. Cazimiro José de Moraes Sarmento - Sr. Professor de primeiras lettras do $2^{\circ}$ Districto de Caixias", utiliza-se do ofício para respaldar o respectivo discurso e, assim, comprovar e legitimar o que foi posto, como forma ser corroborado pelos destinatários. O ofício, por sua vez, mostra parte da legislação excludente que vigorava no período imperial, que, ao determinar que só eram permitidos alunos vacinados, exclui parcela da população que não possui recursos financeiros para se vacinar e, consequentemente, é impedida de frequentar o estabelecimento oficial ou literário. A carta denuncia as doenças e a necessidade de vacina, mostrando as dificuldades de acesso aos médicos e os hábitos sanitários na província. 
Com efeito, havia diversas maneiras utilizadas para se escrever cartas aos jornais no Império. Os recursos empregados para a escrita desse gênero no jornal foram o pseudônimo; o aparecimento da carta entre notícias que aparentemente não estão atreladas ao mesmo assunto; seu mascaramento em outro gênero como o edital e/ou a declaração; o anexo de um documento que confirme e atribua respaldo ao escrito.

A partir desses recursos, professores da província da Paraíba utilizaram a carta para ser fazer presente na discussão sobre a instrução pública no Império. A seguir discutimos como isso ocorreu nas páginas dos jornais de maior circulação na Paraíba imperial.

\section{CORRESPONDÊNCIAS DE QUEIXAS PUBLICADAS NOS JORNAIS DA PARAÍBA IMPERIAL: REPRESENTAÇÕES E PRÁTICAS DOCENTES}

No manual de escrever cartas Código do Bom-Tom ou Regras da Civilidade e de Bem Viver no Século XIX, Roquette (1845) [1875] ensina como se deve redigir cartas de diversos tipos para diversos tipos de pessoas e ocasiões, seguindo os preceitos da boa etiqueta. Entre eles encontra-se a carta de queixa. $\mathrm{O}$ autor orienta que é necessário que o signatário espere que o primeiro momento de fúria, motivo de suas queixas, já tenha passado. Assim como mandava o bom-tom, os professores parecem ter agido conforme as orientações de civilidade para a escrita. Nesse sentido, foram identificadas três cartas de professor em que a escrita é marcada pelas queixas e reclamações. Abaixo se encontra a primeira carta e, concomitantemente, os escritos de queixas de um professor. 
FIGURA 1. Carta de queixas - Gazeta do Sertão

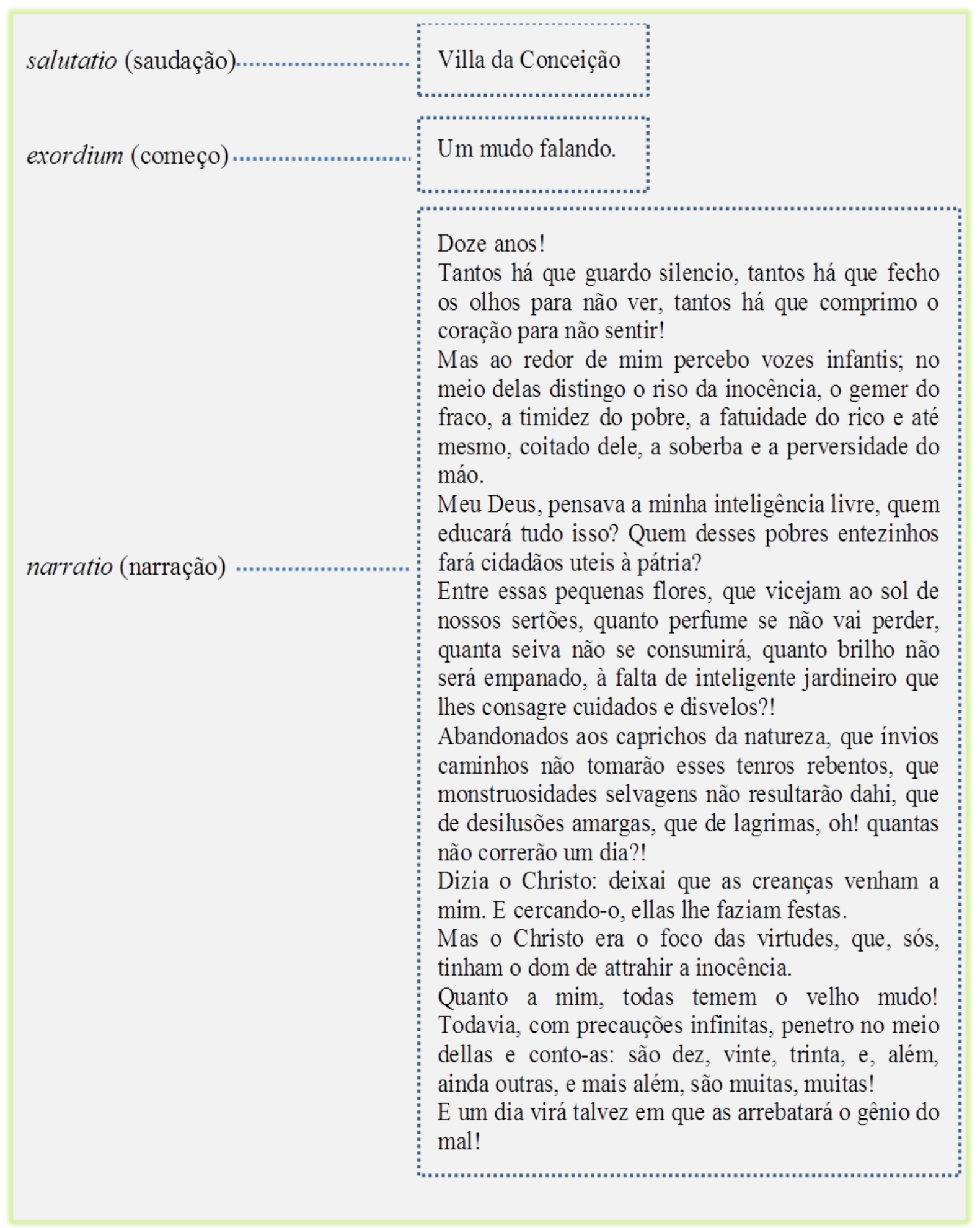




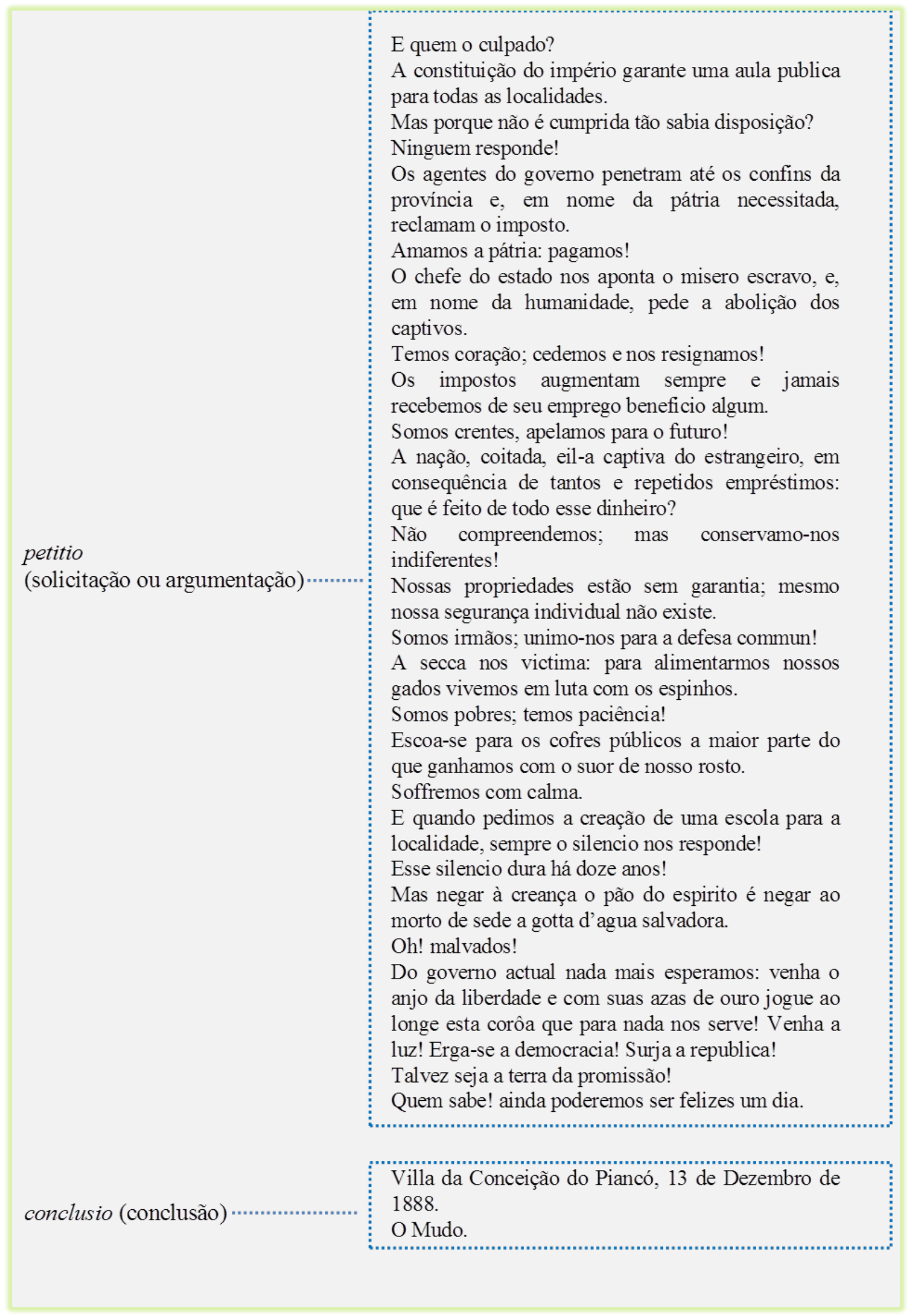

Fonte: GAZETA DO SERTÃO, 11 de janeiro de 1889. 
A carta exposta acima foi escrita em 13 de dezembro de 1888, mas somente foi publicada em 11 de janeiro de 1889, no jornal Gazeta do Sertão ${ }^{5}$. Tal carta, cujo signatário intitula-se "O Mudo", demonstra uma preocupação com a instrução pública, fazendo questionamentos e solicitando mudanças por parte do governo. O signatário explana uma desaprovação pela monarquia e exprime sua esperança na República, que, segundo ele, acabaria com os problemas existentes no Império. A carta publicada no jornal funciona como uma espécie de resistência, para mostrar ao público leitor que a prática docente não está totalmente organizada, como sugere a legislação da província paraibana.

Ao tecer críticas à instrução pública, o signatário mostra-se descontente com os governantes e resiste aos seus desígnios, reclamando e expondo sua opinião no jornal. No entanto, o faz por meio do pseudônimo "O Mudo", que sugere que o professor era um sujeito que não tinha voz na sociedade imperial, ou melhor, que tentavam silenciá-lo. No entanto, a resistência, por meio da escrita da carta de queixas no jornal, mostra a ironia de "um mudo que fala", caracterizando-se como um jogo de palavras utilizado pelo professor para denunciar o estado da instrução pública na província paraibana.

Como dito anteriormente, a assinatura nas cartas dos professores públicos nem sempre existia, sendo comum o uso de pseudônimos. Na carta acima, supomos que o signatário, por apresentar reclamações e reivindicações sobre o cotidiano escolar, é um professor público. O uso de pseudônimo caracteriza o receio de sofrer represálias, já que "é um modo seguro para os 'leitoresescritores-repórteres' apresentarem as suas opiniões" (SENA, 2012, p. 124). A assinatura "O Mudo" poderia se tratar também de um pai de aluno, outro profissional ou qualquer interessado na instrução pública, no entanto, trabalhamos com a hipótese de que a carta seja de um professor, já que o signatário dá indícios de conhecer o cotidiano escolar, quando, dirigindo-se às crianças, ressalta: "todavia, com precauções infinitas, penetro no meio dellas e conto-as: são dez, vinte, trinta, e, além, ainda outras, e mais além, são muitas, muitas!". O "Mudo" traz a imagem de Cristo como forma de sensibilizar seus leitores ao receber tal discurso. Ao se contrapor a Cristo, trazendo-o como "o foco das virtudes", ressalta ser temido. Esse temor traz, a nosso ver, um duplo significado, já que pode estar em alusão às crianças, ou, àqueles que querem silenciá-lo.

\footnotetext{
${ }^{5}$ O jornal Gazeta do Sertão (1880-1891) se apresentava como Órgão Democrata e era publicado semanalmente, impresso geralmente nas sextas-feiras. Este era subscrito na Typographia e Escriptorio dos diretores, por meio dos Senhores I. Joffily e F. Retumba. A tipografia estava situada na Praça Municipal de Campina Grande, $\mathrm{n}^{\circ} 24$. A assinatura do jornal dentro da Comarca custava $6 \$ 000$, o ano, e $3 \$ 500$, o semestre. Fora da comarca e províncias, o jornal era assinado pelo valor de $7 \$ 000$, anuais e $4 \$ 000$ semestrais. O jornal era formado pelas seguintes "Almanak", "Expediente", "Gazeta do Sertão", "Cartas políticas ao Presidente da Província”, "Gazetilha”, "Telegramas", “A Pedido", "Editaes" e "Annuncios".
} 
Um ponto importante que o signatário traz na sequência diz respeito à Lei de 15 de outubro de 1827, quando questiona: "a constituição do império garante uma aula publica para todas as localidades. Mas porque não é cumprida tão sabia disposição?”. Ao afrontar a própria legislação, entendemo-la aqui como dispositivo de poder que comanda a prática docente e o professor reage às disparidades sentidas por ele em seu cotidiano.

Outra característica empregada na carta diz respeito ao uso das pontuações, o que é comum nas cartas de reclamações ou queixas. As interrogações e exclamações são usadas para dar mais ênfase ao que está sendo reclamado, como garante Freire (1801, p. 166), no manual de escrever cartas Secretário Portuguez ou methodo de escrever cartas: "fazem hum bom effeito: primeiramente, porque melhor se move a compaixão a pessoa, a quem escrevemos; e em segundo lugar porque também mostramos mais vivamente a grandeza do nosso desgosto". Assim também, diferentemente da escrita habitual das cartas, cujo texto é redigido em prosa, a carta assinada pelo "Mudo" foi registrada em forma de poema, composta por versos. O professor, signatário da carta, protegido por pseudônimo, escreve em favor de um grupo/categoria, quando emprega o verbo na primeira pessoa do plural, como "esperamos" e/ou "pedimos".

No jornal $O$ Tempo, ${ }^{6}$ de 26 de junho de 1865, uma presumível professora, respaldada pelo pseudônimo Orphã de Caridade, queixa-se, ao escrever uma carta ${ }^{7}$, na qual, ao mesmo tempo em que reclama, denuncia o descaso com que é tratada a instrução pública primária:

\footnotetext{
${ }^{6} \mathrm{O}$ jornal O Tempo (1864-1889) era publicado apenas nas segundas e quintas-feiras. Tinha como proprietário o Senhor Joaquim Pereira Lima, o qual também era Diretor de Redação do citado jornal. Era subscrito pelo valor de 3\$:000 por trimestre, a serem pagos antecipadamente. Sob os anúncios dos assinantes era cobrado um valor de 40 réis por linha. Os interessados em publicar anúncios que não fossem assinantes do jornal deveriam pagar uma taxa de 100 réis. No entanto, o jornal não se responsabilizava pelos escritos de outrem. O jornal O Tempo apresentava as seções "O Tempo", "Gazetilha", "Exterior", "Correspondências", "Comércio", "Movimento do Porto", "Edital" e "Annuncios".

${ }^{7}$ Carta também analisada por Sena (2014), no trabalho Imprensa e Instrução Pública no Império: o modo epistolar nos jornais do Rio de Janeiro e da Paraíba.
} 
FIGURA 2. Carta de queixas - Jornal O Tempo

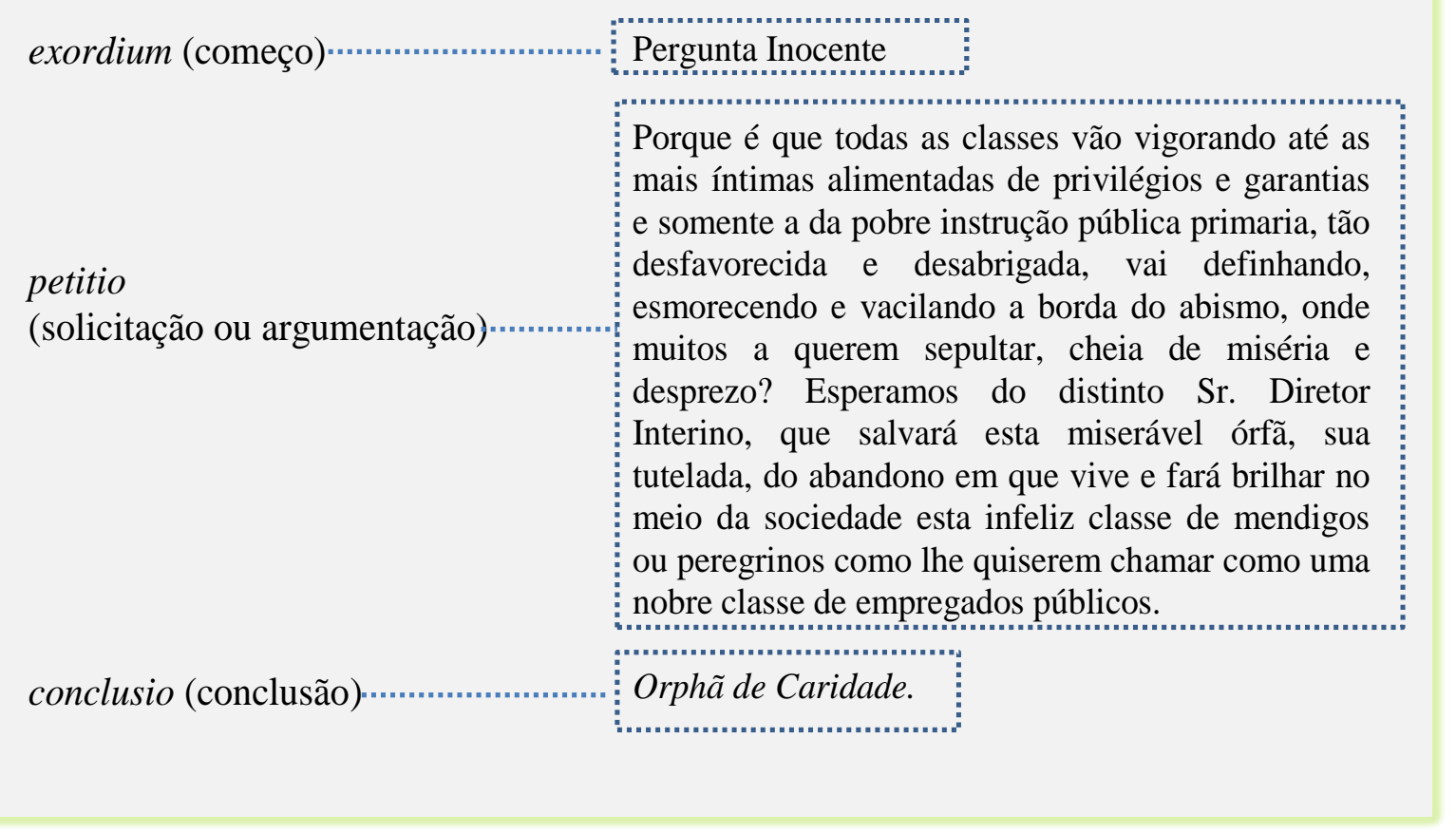

Fonte: O TEMPO, 26 de junho de 1865.

A carta da professora destinada ao Diretor Interino reivindica melhores condições de trabalho para a categoria a qual pertence, que chama de "nobre classe de empregados públicos". Mais uma vez, podemos entender os escritos da carta, agora empreendidos pela "Orphã de Caridade" - possivelmente uma professora pública -, como discurso de resistência ao Estado. A professora da instrução pública primária identifica-se como desabrigada e traz à tona a representação do profissional professor que, embora o discurso legislativo o apreenda como o difusor das luzes, trata-o como "mendigo ou peregrino", conforme sugere a professora.

Assim como a carta supracitada, a carta seguinte, publicada no jornal O Publicador, no dia 13 de novembro de 1886, é endereçada ao Diretor da Instrução Pública. O possível professor, signatário da carta, queixa-se e denuncia a aula pública da villa de Itabaianna, cuja frequência das alunas à aula está escassa. 
FIGURA 3 - Carta de queixas - Jornal O Publicador

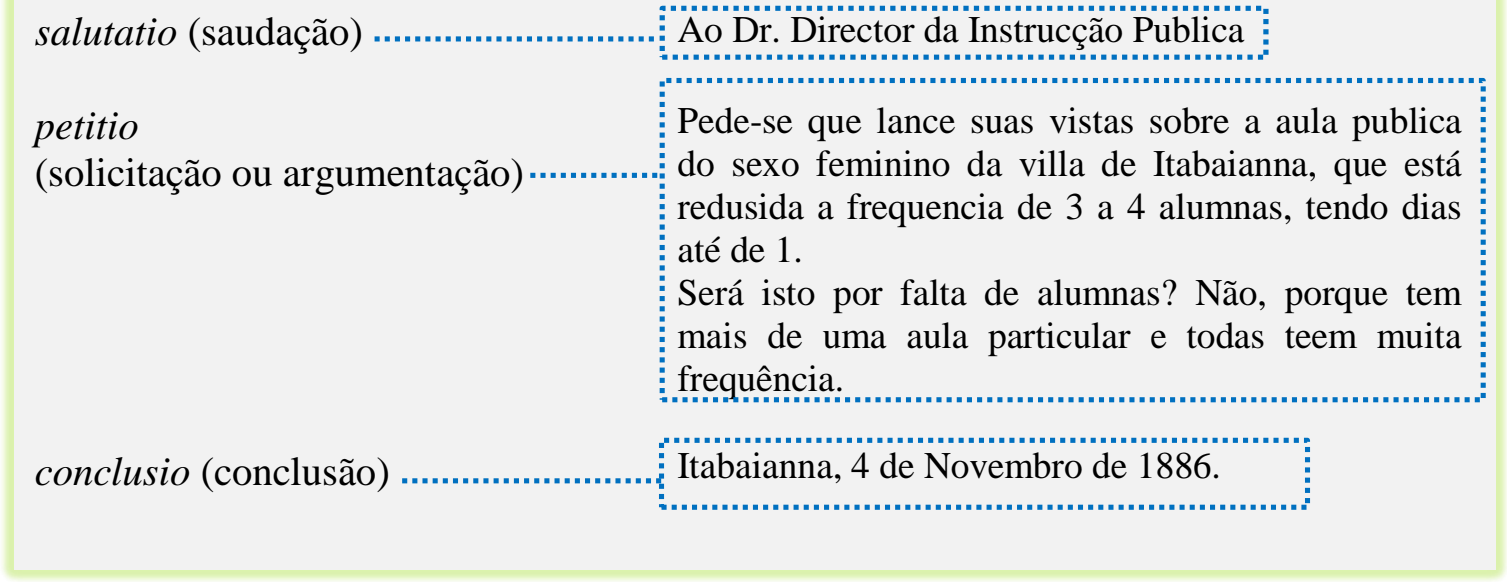

Fonte: O PUBLICADOR, 13 de novembro de 1886.

Por meio do gênero carta nos jornais, os professores reclamaram sobre a situação da instrução pública na província paraibana. Pela escrita das cartas de queixas, podemos observar também algumas representações do professor no período do Império. O "Mudo" e a "Orphã de Caridade", por exemplo, ao reclamarem da falta de escolas e do descaso com a instrução pública demonstram uma imagem do professor que denuncia o estado em que se encontrava a instrução e reivindica melhores condições para o exercício da prática docente.

Por meio desse estudo, foi possível compreender o discurso do professor, caracterizando-o, classificando-o, construindo, assim, representações, que marcaram a forma de ser e de se pensar do professor naquela época. As formas de poder criam discursos que transformam o indivíduo (professor) em sujeito, separando-o/classificando-o em uma denominada identidade. No entanto, esse sujeito não é passivo e vive numa "tensão constante entre a aceitação do poder e a insubmissão da liberdade" (FOUCAULT, 1979, p. 247). O espaço destinado à resistência dos professores foi dado pelos jornais, por meio da escrita de cartas.

Com efeito, o presente trabalho forneceu indícios de como os professores se posicionavam nos jornais na sociedade imperial, desmistificando a ideia de um professor subordinado e pacífico, tal como apregoa a historiografia oficial. Justapondo aos escritos das cartas com outros documentos, verificamos outro discurso acerca das práticas docentes, percebendo que as relações sociais eram muito mais complexas. Nesse sentido, a pesquisa com as cartas nos jornais da Paraíba imperial, o conhecimento desse gênero discursivo e sua relação com a imprensa a partir dos seus signatários os professores da Paraíba imperial - correspondem à apreensão, ainda que parcial, de uma parte da História da Educação paraibana. 


\section{REFERÊNCIAS}

A PROVÍNCIA: Órgão da Província Liberal. Pernambuco, 18 fev. 1874. Disp.: <http://hemerotecadigital.bn.br/>. Acesso em: 18 abr. 2014.

, Pernambuco, 21 fev. 1874. Disp.: <http://hemerotecadigital.bn.br/>. Acesso em: 17 mai. 2014.

BRASIL. Lei de 15 de outubro de 1827. Manda criar escolas de primeiras letras em todas as cidades, vilas e lugares mais populosos do Império, 1827. Disp.: <http://www.planalto.gov.br/ccivil_03/leis/LIM/LIM-15-10-1827.htm>. Acesso em: 24 jan. 2015.

CHARTIER, Roger. O mundo como representação. In: Revista das Revistas. São Paulo: Instituto de Estudos Avançados da Universidade de São Paulo, 1991. Disp.: <http://www.scielo.br/scielo.php?pid=S010340141991000100010\&script=sci_arttext>. Acesso em: 15 ago. 2014.

FOUCAULT, Michel [1970]. A ordem do discurso. Paris: Éditions Gallimard, 1971.

. Microfísica do Poder. 14. ed. Rio de Janeiro: Edições Graal, 1979.

FREIRE, Francisco José. Secretário Portuguez ou methodo de escrever cartas. [1801] Lisboa: Typografia Rollandiana, 1823.

FREITAS, Marcos C. Por quem os sinos dobram? As cartas pastorais e a contribuição da história da educação à história das mentalidades. In: BASTOS, Maria Helena C. et al. (Org.). Destinos das letras: História, educação e escrita epistolar. Passo Fundo: UPF, 2002.

GAZETA DO SERTÃO. Um mudo falando. Paraíba, 11 de janeiro de 1889.

O GOVERNISTA PARAHYBANO. Paraíba, 6 jul. 1850. Disp: <http://www.cchla.ufpb.br/jornaisefolhetins>. Acesso em: 9 maio 2014

O PUBLICADOR. Paraíba, 13 nov. 1886. Disp.: <http://hemerotecadigital.bn.br/>. Acesso em: 4 maio 2014.

O TELÉGRAFO. Maranhão, 9 jun. de 1849. Disp.: <http://hemerotecadigital.bn.br/>. Acesso em: 18 fev. 2014.

O TEMPO. Pergunta Innocente. Paraíba, 26 de junho de 1865.

PARAÍBA. Lei 20, de 6 de maio de 1837. In: PINHEIRO, Antonio C.; CURY, Cláudia E. (Orgs.). Leis e Regulamentos da instrução da Paraíba no período Imperial. Brasília: MEC/INEP/SBHE, 2004. (Col. Documentos da Educação Brasileira).

. Regulamento, 20 de janeiro de 1849. In:

Regulamento, 1860. In:

. Regulamento $\mathrm{n}^{\mathrm{o}}$ 36, 26 de junho de 1886. In:

. Província. Relatório apresentado à Assembleia Legislativa Provincial da Parahyba do Norte, 1839.

. [1875]. Código do Bom Tom ou Regras da Civilidade e de Bem Viver no Século XIX. 3. ed. Paris, 1845.

PEIXOTO, Flávia M. A Escola Normal oficial de Pernambuco. 2006. Dissertação (Mestrado). Disp.: <http://repositorio.ufpe.br/xmlui/bitstream/handle/123456789/4440/arquivo5298_1.pdf?sequence=1>. Acesso em: 22 jan. 2015.

SENA, Fabiana. As cartas sobre instrução pública nos jornais paraibanos do Império. In: PINHEIRO, Antonio Carlos F.; CURY, Claúdia E. (Orgs.). Histórias da Educação da Paraíba: Rememorar e Comemorar. João Pessoa: Editora Universitária/ UFPB, 2012.

. Imprensa e Instrução Pública no Império: o modo epistolar nos jornais do Rio de Janeiro e da Paraíba. In: Revista Brasileira de História da Educação, Maringá, v. 14, n. 1 (34), p. 73-97, jan./abr. 2014. Disp.: <http://www.rbhe.sbhe.org.br/index.php/rbhe/article/viewFile/451/pdf_12>. Acesso em: 26 jan. 2015. 


\section{RESUMO}

O trabalho objetiva analisar as representações e práticas docentes nas cartas de queixas publicadas nos jornais Publicador, O Tempo e Gazeta do Sertão da província Paraíba, no período de 1864 a 1889. As cartas foram analisadas a partir das perspectivas do conteúdo e da forma de escrita, utilizando como fonte os relatórios de províncias, leis, regulamentos da província da Paraíba e os manuais de escrever cartas, para restituir o discurso no tempo da sua história. Para a análise desse estudo também foi utilizada a perspectiva teórico metodológica de Michel Foucault por meio dos conceitos de poder e resistência, bem como a de Roger Chartier com o conceito de representação. As cartas analisadas apresentam um veículo de manifestação do professor a respeito da sua prática, de modo que denuncia a situação da instrução pública na província paraibana. Com efeito, este estudo demonstrou que, por meio das cartas de professores publicadas nos jornais, havia um discurso de resistência em confronto com os dispositivos de poder atribuídos a esses sujeitos.

Palavras-chave: Cartas. Professores. Jornais.

\section{REPRESENTATIONS AND PRACTICES IN THE FACULTY OF PARAÍBA PROVINCE COMPLAINTS LETTERS IN EMPIRE}

\section{ABSTRACT}

The work aims to analyze the representations and teaching practices in the letters of complaints published in the newspapers publisher, Publicador, O Tempo e Gazeta do Sertão, from 1864 to 1889 . The letters were analyzed from the perspective of the content and form of writing using as source the provinces reports, laws, Paraiba province of regulations and manuals to write letters, to bring the speech at the time of its history. For the analysis of this study it was also used methodological theoretical perspective of Michel Foucault through the concepts of power and resistance, as well as Roger Chartier with the concept of representation. The analyzed letters have a vehicle of manifestation of the teacher about your practice so that denounces the state of public education in Paraiba province. Indeed, this study demonstrated that, through letters of teachers published in the newspapers, there was a discourse of resistance in comparison with the devices of power allocated to these subjects.

Keywords: Letters. Teachers. Newspapers.

Submetido em: Set. 2016

Aprovado em: Fev. 2017*

\footnotetext{
${ }^{(*)}$ Este trabalho foi financiado pela CAPES.
} 